\title{
VACAS TERMINADAS EM CAMPO NATIVO SUPLEMENTADAS COM FARELO DE TRIGO OU FARELO DE ARROZ INTEGRAL CONTENDO OU NÃO MONENSINA SÓDICA
}

\author{
Finished cows in native grass supplemented with wheat bran or \\ rice bran with or without sodic monensin \\ Milene Puntel Osmari ${ }^{1}$, Miguelangelo Ziegler Arboitte ${ }^{2}$, Ivan Luiz Brondani ${ }^{3}$, \\ Fernando Kuss', Dari Celstino Alves Filho ${ }^{5}$, João Restle ${ }^{6}$
}

\begin{abstract}
RESUMO
Foram avaliados o desempenho, composição física, rendimento de cortes comerciais e a qualidade da carne de vinte e oito vacas Charolês, Nelore e suas cruzas, com peso vivo médio inicial de $409 \mathrm{~kg}$, terminadas em campo nativo com alta participação de Eragrostis plana Nees., suplementadas por 99 dias com farelo de trigo (FTR) ou farelo de arroz integral (FAI), a 0,5\% do peso vivo na matéria seca, com ou sem a inclusão de monensina sódica, separados em grupos de sete para a composição dos tratamentos. O uso de farelo de trigo proporcionou melhor conformação da carcaça $(\mathrm{P}<0,05)$, classificando essa como "regular +" $(9,90$ pontos). As demais características estudadas não foram influenciadas $(\mathrm{P}>0,05)$ pelo tipo de suplemento. A inclusão de monensina sódica não proporcionou diferenças significativas $(\mathrm{P}>0,05)$ nas variáveis estudadas.
\end{abstract}

Termos para indexação: Aditivo, Charolês, Nelore, suplementação energética, terminação de vacas.

\section{ABSTRACT}

The performance, physical composition, income of commercial cuts the quality of the meat of twenty eight cows Charolais, Nellore and its cross, were evaluated with initial average live weight of $409 \mathrm{~kg}$, finished in native grass with high participation of Eragrostis plana Nees., supplemented per 99 days with wheat bran or rice bran $0.5 \%$ of the alive weight in the DM with or without the inclusion of sódica monensina. The use of wheat bran provided a better conformation of the carcass $(\mathrm{P}<0.05)$, classifying it as "regulate +" (9.90 points). The others characteristic studied was not influenced $(\mathrm{P}>0.05)$ by the type of supplement. The inclusion of sodic monensin did not provide significant differences $(\mathrm{P}>0.05)$ in the variable studied.

Index terms: Addictive, Charolais, cow finishing, energetic supplementation, Nellore.

(Recebido em 27 de março de 2008 e aprovado em 29 de julho de 2008)

\section{INTRODUÇÃOO}

Estima-se que a área da gramínea invasora capim annoni (Eragrostis plana Nees.) nos campos nativos do Rio Grande do Sul, é de 2 milhões de ha e apresenta expansão estimada em 14.000 hectare/ano (ZILLER \& ROSA, 2005). Este é um dos problemas enfrentados pelos pecuaristas que buscam melhorar os índices de produtividade. O campo nativo do Rio Grande do Sul tem como característica grande diversidade botânica, boa produção de biomassa em certas épocas do ano (primavera - verão) e valor nutritivo médio. Cerca de $88 \%$ dos bovinos encontram-se em campo nativo não melhorados (NABINGER et al., 2005) e com baixos índices de produtividade.

Uma alternativa para melhorar os índices produtivos é a suplementação em campo nativo durante o outono, ferramenta essa que pode proporcionar aumento de peso dos animais (melhor aporte nutritivo) e auxiliar no ajuste de carga animal, por meio da substituição do pasto ingerido pelo suplemento. A partir do final do verão até o término do inverno, a pastagem nativa do Rio Grande

\footnotetext{
Zootecnista, Mestranda - Departamento de Zootecnia/DZ - Universidade Federal de Santa Maria/UFSM - Avenida Roraima, 1000 - Camobi - 97105 900 - Santa Maria, RS - mileneosmari@yahoo.com.br - Bolsista Capes

2Zootecnista, Doutorando em Zootecnia - Departamento de Zootecnia/DZ - Universidade Federal de Santa Maria/UFSM - Avenida Roraima, 1000 Camobi - 97105-900 - Santa Maria, RS - marboitte@hotmail.com - Bolsista CAPES

${ }^{3}$ Zootecnista, Doutor, Professor Adjunto - Departamento de Zootecnia/DZ - Universidade Federal de Santa Maria/UFSM - Avenida Roraima, 1000 Camobi - 97105-900 - Santa Maria, RS - ilbrondani@yahoo.com.br

${ }^{4}$ Zootecnista, Doutor - Faculdade de Medicina Veterinária/FMV - Universidade Federal do Pará/UFPA - Avenida Maximino Porpino da Silva, 1000 68473-080 - Castanhal, PA - kuss@ufpa.br

${ }^{5}$ Engenheiro Agrônomo, Doutor, Professor(a) - Departamento de Zootecnia/DZ - Universidade Federal de Santa Maria/UFSM - Avenida Roraima, 1000 Camobi - 97105-900 - Santa Maria, RS - alvesfilho@smail.ufsm.br

${ }^{6}$ Engenheiro Agrônomo, PhD. Professor - Departamento de Zootecnia/DZ - Universidade Federal de Santa Maria/UFSM - Avenida Roraima, 1000 Camobi - 97105-900 - Santa Maria, RS - jorestle@terra.com.br
} 
do Sul sofre redução gradual na sua qualidade e disponibilidade, o que foi constatado por Alves Filho (1995) e Vaz (1998), fazendo assim, com que esse período seja o mais adequado para efetuar a suplementação, visando corrigir ou amenizar o déficit qualitativo da pastagem nativa.

O farelo de arroz integral (FAI) e o farelo de trigo (FTR) são subprodutos das indústrias beneficiadoras de grãos, muito utilizados em confinamento e na suplementação de bovinos. O FTR tem valor protéico superior ao FAI que, por sua vez, possui valor energético um pouco maior. Suas características bromatológicas são diferentes entre si e, por conseguinte, têm diferentes comportamentos degradativos no rúmen, podendo influenciar o desempenho animal (RESTLE et al., 2006). As composições bromatológicas desses produtos são dependentes das condições de armazenamento e da inclusão ou não da casca, principalmente no FAI. Tal inclusão aumenta os teores de sílica, lignina e fibra bruta, o que deprecia o seu valor nutritivo. No FTR, pode-se encontrar elevados níveis de proteína bruta e fósforo, além de ser um suplemento de alta palatabilidade.

Uma alternativa para melhorar o desempenho animal é a inclusão de ionóforos no suplemento. Dentre os ionóforos, a monensina sódica tem sido empregada amplamente na alimentação de ruminantes, visto que reduz o desenvolvimento de bactérias gram-positivas, que são produtoras primárias de acetato, butirato, $\mathrm{H}_{2}$, beneficiando a produção de ácido propiônico (LANA \& RUSSELL, 2001), que, segundo Roso \& Restle (2001), é energeticamente mais eficiente.

Objetivou-se, neste trabalho, avaliar o desempenho, a composição física, as características da carcaça e a qualidade da carne de vacas de descarte, terminadas em pastagem nativa com alta participação de capim annoni (Eragrostis plana Nees.), suplementadas com farelo de trigo ou farelo de arroz integral, associados ou não à monensina sódica.

\section{MATERIALE MÉTODOS}

O experimento foi conduzido no Laboratório de Bovinocultura de Corte do Departamento de Zootecnia da Universidade Federal de Santa Maria, localizado na latitude de $29^{\circ} 43^{\prime}$ 'Sul e longitude $53^{\circ} 42^{\prime}$ Oeste. O período de alimentação em campo nativo composto por Eragrostis plana Nees, compreendeu de 26 de fevereiro a 5 de junho, totalizando 99 dias. Foram utilizadas 28 vacas de descarte dos grupos genéticos Charolês $(\mathrm{C})$, Nelore $(\mathrm{N})$ e suas cruzas, com idade média de sete anos e peso vivo médio inicial de $409 \mathrm{~kg}$, com carga animal média inicial de $255 \mathrm{~kg} /$ ha e final de $301 \mathrm{~kg} / \mathrm{ha}$.

Os animais foram distribuídos em número de sete em cada tratamento: suplementação com $0,5 \%$ do peso vivo (PV) na matéria seca (MS) de farelo de arroz integral; farelo de arroz integral + monensina; farelo de trigo e farelo de trigo + monensina. Nos tratamentos onde foi incluída a monensina sódica, a oferta diária dessa foi de $150 \mathrm{mg} /$ animal. Os animais receberam suplementação mineral " $a d$ libitum", sendo utilizado sal comum e fosfato bicálcico, na proporção 1:1.

A cada 28 dias foram realizadas avaliações do resíduo das pastagens, através da técnica da dupla amostragem (WILM et al., 1944), com 25 amostras (0,25 m²/ amostra) estimadas visualmente nos 45 ha da área. Dessas, cinco amostras foram cortadas rente ao solo e pesadas individualmente. Em seguida, retirou-se uma subamostra composta para determinação do teor de matéria parcialmente seca. Dessas amostras, foram determinados os teores de MS e de proteína bruta (PB) segundo o AOAC (1984) e FDN (SOEST, 1991). A pastagem teve disponibilidade média da MS de $3.367 \mathrm{~kg} / \mathrm{ha}, 5,2 \%$ PB e $81,4 \%$ FDN.

A taxa de acúmulo da pastagem foi avaliada em períodos de 28 dias, utilizando-se três gaiolas de exclusão ao pastejo, adotando-se o método do triplo emparcelamento (MORAES, 1991). A produção total de MS foi obtida pelo somatório das produções dos períodos (taxa de acumulação $\mathrm{x}^{\circ}$ de dias) mais o resíduo inicial no momento da entrada dos animais na pastagem.

As pesagens dos animais foram efetuadas ao início e final do experimento, com pesagens intermediárias a cada 28 dias, antecedidas de um jejum de sólidos de 14 horas. Ao final de cada período experimental, eram feitos os ajustes da quantidade de suplemento a ser fornecido aos animais. Por ocasião da pesagem, foi realizada a avaliação da condição corporal individual, utilizando-se a metodologia descrita por Bavera \& Peñaforte (2005), onde: 1-muito magro, 2-magro, 3-médio, 4-gordo e 5-muito gordo.

Após 99 dias de experimento, o peso de abate foi determinado na fazenda, após um jejum de sólidos e líquidos de 14 horas. Em seguida, as vacas foram transportadas até um frigorífico comercial, distante $25 \mathrm{~km}$ da propriedade. $\mathrm{O}$ abate $\mathrm{e}$ as avaliações de carcaça foram realizadas conforme metodologia descrita por Arboitte et al. (2004). Para determinação da quantidade dos tecidos (músculo, gordura 
e osso) e qualidade da carne utilizou-se metodologia proposta por Müller (1987).

O delineamento experimental foi o de blocos ao acaso para grupo genético com esquema fatorial $2 \times 2$ (duas fontes de suplementação x duas níveis de monensina), com sete repetições. Cada grupo genético representou um bloco. Os dados foram submetidos à análise de variância e teste " $t$ ", em nível de 5\% de significância. Nesse estudo não se avaliou a interação da pastagem x suplemento.

\section{RESULTADOS E DISCUSSÃO}

A interação entre o suplemento e os níveis de monensina foi retirada do modelo por não apresentarem significância $(\mathrm{P}>0,05)$. Na Tabela 1 , estão os pesos vivos médio inicial (PI) e final (PF), ganho médio diário de peso (GMD), escore corporal inicial (ECI) e final (ECF) e ganho de escore corporal (GEC), de acordo com os tratamentos.

$\mathrm{O}$ aditivo e o tipo de suplemento não influenciaram o GMD ( $\mathrm{P}>0,05)$, indicando que o uso do FAI e do FTR, com ou sem monensina, podem proporcionar respostas de ganho de peso similares, e que a escolha pela utilização de um ou de outro dependerá da disponibilidade do produto e principalmente do valor de aquisição.

Em vacas adultas na terminação, o ganho de peso dá-se, basicamente, na forma de tecido adiposo, que apresenta menor teor de água e elevada concentração energética, exigindo maior consumo de energia para promover o ganho de peso (RESTLE et al., 2001). A utilização de $0,5 \%$ PV de suplementos, com ou sem monensina, promoveram GMD de $0,775 \mathrm{~kg}$, durante o período de outono. Ganhos de peso diários de 0,217 e
$0,115 \mathrm{~kg} / \mathrm{dia}$, para ofertas de forragens de 12 e $16 \%,(\mathrm{Kg}$ MS/100 Kg PV), respectivamente, durante o período de outono, foram relatados por Soares et al. (2005). Em outra pesquisa, na mesma estação climática do ano, Moojen (1991) verificou GMD negativo, para animais em pastejo em campo nativo.

O ganho de peso vivo por hectare durante o período experimental foi de $50,87 \mathrm{~kg}$, ficando esse acima dos observados por Crancio et al. (2006) e Moojen (1991), que relataram ganhos negativos; e dos 19,2 e $3,3 \mathrm{~kg} / \mathrm{ha}$ observados por Soares et al. (2005).

Pesquisas com monensina em campo nativo são raras. A utilização desse aditivo ocorreu, principalmente, em pesquisas que utilizavam pastagens cultivadas de inverno ou em sistemas de confinamento. Trabalhando com novilhas e vacas em confinamento, recebendo (150 $\mathrm{mg} / \mathrm{animal} / \mathrm{dia}$ ) ou não na dieta monensina, Restle et al. (2001) obtiveram redução no GMD, para as vacas que recebiam o aditivo. Os autores justificaram que vacas adultas podem apresentar paladar mais apurado, o que diminuiu o consumo de MS na presença da monensina.

Os resultados encontrados estão de acordo com os verificados por Kuss et al. (2008) e Restle et al. (2001), os quais relataram que a presença de monensina sódica à dieta não traz benefício quanto ao desempenho de vacas terminadas em confinamento, pois atua como limitante no consumo de alimento e, consequientemente, no ganho de peso.

Para o EC e GEC também não foram verificadas influência $(\mathrm{P}>0,05)$ da monensina e do tipo de suplemento, o mesmo observado por Restle et al. (2001), em vacas confinadas, e Freitas et al. (2005), em novilhas em pastagem

Tabela 1 - Médias e respectivos erros padrões de peso inicial (PI), peso final (PF), ganho médio diário (GMD), escore corporal inicial (ECI), escore corporal final (ECF) e ganho de escore corporal (GEC) de acordo com os tratamentos de vacas, suplementadas com concentrado energético, associado ou não à monensina sódica.

\begin{tabular}{lcccccc}
\hline \multirow{2}{*}{ Características } & \multicolumn{3}{c}{ Tipo de suplemento } & \multicolumn{3}{c}{ Monensina sódica } \\
\cline { 2 - 7 } & FAI $_{1}$ & FTR $_{2}$ & $\mathrm{P}$ & Com $_{3}$ & Sem $_{4}$ & $\mathrm{P}$ \\
\hline PI, kg & $409,64 \pm 6,23$ & $409,28 \pm 6,23$ & 0,97 & $409,43 \pm 6,23$ & $409,50 \pm 6,23$ & 0,99 \\
PF, kg & $491,07 \pm 7,32$ & $491,36 \pm 7,32$ & 0,88 & $491,57 \pm 7,32$ & $490,86 \pm 7,32$ & 0,94 \\
GMD, kg/dia & $0,775 \pm 0,06$ & $0,776 \pm 0,06$ & 0,98 & $0,785 \pm 0,06$ & $0,765 \pm 0,06$ & 0,81 \\
ECI $^{a}$, pontos & $3,07 \pm 0,04$ & $3,07 \pm 0,04$ & 0,98 & $3,10 \pm 0,04$ & $3,04 \pm 0,04$ & 0,28 \\
ECF $^{\text {a }}$, pontos & $3,38 \pm 0,04$ & $3,37 \pm 0,04$ & 0,85 & $3,39 \pm 0,04$ & $3,36 \pm 0,04$ & 0,64 \\
GEC, pontos & $0,31 \pm 0,01$ & $0,30 \pm 0,01$ & 0,65 & $0,29 \pm 0,01$ & $0,32 \pm 0,01$ & 0,05 \\
\hline
\end{tabular}

\footnotetext{
${ }^{1}$ Farelo de arroz integral;

${ }^{2}$ Farelo de trigo;

${ }^{3}$ Suplemento com monensina;

${ }^{4}$ Suplemento sem monensina.

a 1-muito magro, 2-magro, 3-médio, 4-gordo, 5-muito gordo
} 
cultivada de inverno. O EC é uma medida subjetiva que auxilia na determinação do grau de acabamento dos animais, sendo bastante influenciável pelo GMD, que não apresentou diferença $(\mathrm{P}>0,05)$ entre os tratamentos. No entanto, os animais aumentaram o EC no final do experimento.

As características quantitativas da carcaça, que podem ser observadas na Tabela 2, não foram influenciadas ( $\mathrm{P}>0,05)$ pelo tipo de suplemento fornecido e nem pela inclusão da monensina sódica à dieta. Autores como Boling et al. (1977) e Moraes et al. (1993), também não encontraram diferenças quanto à utilização ou não de monensina na dieta de bovinos, sobre as características da carcaça.

A conformação da carcaça apresentou diferenças significativas $(\mathrm{P}<0,05)$ quanto ao tipo de suplemento, no qual as vacas alimentadas com FTR apresentaram conformação classificada como "regular +" (MÜLLER, 1987) e as alimentadas com FAI "regular -". Quando se adicionou a monensina na dieta, a conformação não apresentou diferença significativa $(\mathrm{P}>0,05)$ ficando essa classificada como "regular +". A característica de conformação da carcaça é importante e de caráter qualitativo e se correlaciona positivamente com a quantidade de músculo presente (MÜLLER, 1987). Encontrou-se correlação positiva de $0,051(\mathrm{P}>0,05)$ entre a conformação e a porção comestível, indicando que, quanto melhor a conformação, maior a participação de músculo, concordando com Müller (1987), onde carcaças de melhor conformação tendem a apresentar menor proporção de osso e maior de porção comestível.

Para as características de maciez, palatabilidade, suculência, textura, cor, marmoreio, força de cisalhamento, quebra ao descongelamento e à cocção da carne (Tabela 3) também não foram observadas diferenças $(\mathrm{P}>0,05)$, tanto para o tipo de suplemento quanto para inclusão ou não de monensina.

Tabela 2 - Médias e respectivos erros padrões para o peso de carcaça quente (PCQ) e fria (PCF), rendimento de carcaça quente (RCQ) e fria (RCF), espessura de gordura subcutânea em mm (EGS), área de Longissimus dorsi em $\mathrm{cm}^{2}$ (AOL), porcentagem de dianteiro (PDIANT), de costilhar (PCOST) e de traseiro (PTRAS) na carcaça, porcentagem de músculo (MCARC\%), de gordura (GCARC\%) e osso (OCARC\%) na carcaça, relação da porção comestível (RELPCO) e conformação (CONF) da carcaça e pontos de vacas suplementadas com concentrado energético associado ou não à monensina sódica.

\begin{tabular}{lcccccc}
\hline \multirow{2}{*}{ Características } & \multicolumn{3}{c}{ Tipo de suplemento } & \multicolumn{3}{c}{ Monensina sódica } \\
\cline { 2 - 7 } & $\mathrm{FAI}_{1}$ & $\mathrm{FTR}_{2}$ & $\mathrm{P}$ & $\mathrm{Com}_{3}$ & Sem $_{4}$ & $\mathrm{P}$ \\
\hline PCQ$(\mathrm{kg})$ & $263,14 \pm 9,8$ & $261,98 \pm 10,20$ & 0,88 & $262,50 \pm 9,80$ & $262,63 \pm 10,20$ & 0,81 \\
PCF(kg) & $263,08 \pm 9,86$ & $261,77 \pm 10,26$ & 0,89 & $262,41 \pm 9,86$ & $262,44 \pm 10,26$ & 0,82 \\
RCQ$(\mathrm{kg})$ & $51,83 \pm 0,96$ & $52,70 \pm 1,00$ & 0,89 & $52,25 \pm 0,96$ & $52,28 \pm 1,00$ & 0,59 \\
RCF(kg) & $51,80 \pm 0,94$ & $52,66 \pm 0,98$ & 0,89 & $52,22 \pm 0,94$ & $52,24 \pm 0,98$ & 0,58 \\
EGS(mm) & $5,14 \pm 0,55$ & $5,05 \pm 0,57$ & 0,51 & $5,42 \pm 0,55$ & $4,76 \pm 0,57$ & 0,15 \\
AOL(cm $\left.{ }^{2}\right)$ & $72,47 \pm 3,26$ & $72,42 \pm 3,39$ & 0,71 & $75,30 \pm 3,26$ & $69,59 \pm 3,39$ & 0,39 \\
PDIAN(\%) & $33,92 \pm 0,40$ & $33,48 \pm 0,42$ & 0,26 & $33,61 \pm 0,40$ & $33,79 \pm 0,42$ & 0,97 \\
PCOST(\%) & $15,12 \pm 0,28$ & $15,15 \pm 0,29$ & 0,79 & $15,26 \pm 0,28$ & $15,01 \pm 0,29$ & 0,71 \\
PTRAS(\%) & $50,95 \pm 0,39$ & $51,36 \pm 0,40$ & 0,36 & $51,13 \pm 0,40$ & $51,18 \pm 0,40$ & 0,75 \\
MCARC(\%) & $65,26 \pm 1,69$ & $64,06 \pm 1,76$ & 0,79 & $64,47 \pm 1,70$ & $64,86 \pm 1,76$ & 0,71 \\
GCARC(\%) & $20,34 \pm 1,19$ & $20,35 \pm 1,24$ & 0,77 & $20,81 \pm 1,20$ & $19,88 \pm 1,24$ & 0,40 \\
OCARC(\%) & $14,83 \pm 0,57$ & $15,71 \pm 0,60$ & 0,32 & $15,06 \pm 0,57$ & $15,49 \pm 0,60$ & 0,62 \\
RELPCO & $5,83 \pm 0,22$ & $5,52 \pm 0,23$ & 0,38 & $5,774 \pm 5,77$ & $5,581 \pm 5,58$ & 0,59 \\
CONF & $8,85 \pm 0,35$ & $9,90 \pm 0,36$ & 0,0499 & $9,571 \pm 0,35$ & $9,160 \pm 0,36$ & 0,53 \\
\hline
\end{tabular}

\footnotetext{
${ }^{1}$ Farelo de arroz integral;

${ }^{2}$ Farelo de trigo;

${ }^{3}$ Suplemento com monensina;

${ }^{4}$ Suplemento sem monensina;

A 1-3: inferior; 4-6: má; 7-9: regular; 10-12: boa; 13-15: muito boa; 16-18: superior.
} 
Tabela 3 - Características e respectivos erros padrões de cor, textura, marmoreio, maciez, palatabilidade, suculência em pontos, força de cizalhamento $\mathrm{kgf} / \mathrm{cm}^{3}$, porcentagem de quebra ao descongelamento e à cocção da carne de vacas suplementadas com concentrado energético associado ou não à monensina sódica.

\begin{tabular}{|c|c|c|c|c|c|c|}
\hline \multirow{2}{*}{ Características } & \multicolumn{3}{|c|}{ Tipo de Suplemento } & \multicolumn{3}{|c|}{ Monensina sódica } \\
\hline & $\mathrm{FAI}_{1}$ & $\mathrm{FTR}_{2}$ & $\mathrm{P}$ & $\mathrm{Com}_{3}$ & $\mathrm{Sem}_{4}$ & $\mathrm{P}$ \\
\hline Cor $^{\mathrm{a}}$ (pontos) & $2,79 \pm 0,25$ & $2,69 \pm 0,26$ & 0,94 & $2,78 \pm 0,25$ & $2,69 \pm 0,26$ & 0,94 \\
\hline Textura $^{\mathrm{a}}$ (pontos) & $2,71 \pm 0,24$ & $2,84 \pm 0,25$ & 0,51 & $2,71 \pm 0,24$ & $2,84 \pm 0,25$ & 0,51 \\
\hline Marmoreio $^{\mathrm{b}}$ (pontos) & $4,14 \pm 0,39$ & $3,89 \pm 0,40$ & 0,59 & $4,21 \pm 0,39$ & $3,82 \pm 0,40$ & 0,44 \\
\hline Maciez $^{\mathrm{c}}$ (pontos) & $6,17 \pm 0,22$ & $6,17 \pm 0,23$ & 0,84 & $6,21 \pm 0,22$ & $6,13 \pm 0,23$ & 0,68 \\
\hline Palatabilidade $^{c}$ (pontos) & $6,96 \pm 0,33$ & $7,45 \pm 0,35$ & 0,19 & $7,32 \pm 0,33$ & $7,10 \pm 0,35$ & 0,88 \\
\hline Suculência ${ }^{\mathrm{c}}$ (pontos) & $6,82 \pm 0,19$ & $7,16 \pm 0,2$ & 0,26 & $7,11 \pm 0,19$ & $6,87 \pm 0,2$ & 0,40 \\
\hline Força de Cisalhamento $\left(\mathrm{kgf} / \mathrm{cm}^{3}\right)$ & $3,80 \pm 0,26$ & $3,68 \pm 0,27$ & 0,78 & $3,62 \pm 0,26$ & $3,85 \pm 0,27$ & 0,55 \\
\hline Quebra ao descongelamento (\%) & $0,09 \pm 0,01$ & $0,10 \pm 0,01$ & 0,30 & $0,09 \pm 0,01$ & $0,09 \pm 0,01$ & 0,56 \\
\hline Quebra à Cocção (\%) & $0,22 \pm 0,02$ & $0,19 \pm 0,02$ & 0,26 & $0,20 \pm 0,02$ & $0,22 \pm 0,02$ & 0,43 \\
\hline
\end{tabular}

${ }^{1}$ Farelo de arroz integral;

${ }^{2}$ Farelo de trigo;

${ }^{3}$ Suplemento com monensina;

${ }^{4}$ Suplemento sem monensina;

a 1- escura, muito grosseira; 2- vermelha-escura, grosseira; 3- vermelha levemente escura, levemente grosseira; 4- vermelha, fina; 5vermelho viva, muito fina.

${ }^{\mathrm{b}}$ Escala de pontos de 1 a 18 (1-traços; 18-abundante).

${ }^{\mathrm{c}}$ Escala de 1 a 9 pontos (1- extremamente dura, extremamente impalatável e sem suculência; 9 - extremamente macia, extremamente saborosa e muito suculenta).

A cor da carne é dependente da idade do animal e do stress pré-abate e a marmorização é fator dependente do grau de acabamento, da raça e do nível energético da dieta. Como esses fatores foram semelhantes para os tratamentos, era de se esperar que essas variáveis não apresentassem diferenças ( $\mathrm{P}>0,05)$. Menezes et al. (2006) também não verificaram influência da monensina na cor e no marmoreio da carne para novilhos terminados em confinamento. Os autores trabalharam com $200 \mathrm{mg}$ de monensina/animal/dia.

A idade média do abate das vacas foi de sete anos, o que pode interferir na maciez da carne (MÜLLER, 1987). Todavia, observa-se que a força necessária para o rompimento das fibras musculares apresentou valores médios de $3,7 \mathrm{kgf} / \mathrm{cm}^{3}$, considerando a carne como macia. A maciez verificada por meio da realização de um painel de degustação apresentou valores médios de 6,17 pontos e também classifica essa carne como macia acima da média. O mesmo foi observado para a suculência e a palatabilidade, que também apresentaram valores de 7,21 e 6,99 pontos, respectivamente.

A palatabilidade da carne não foi influenciada pala presença da monensina na dieta, discordando dos resultados de Menezes et al. (2006), que observaram que a palatabilidade da carne diminuiu à medida que aumentou a participação do aditivo na dieta. Esses autores especularam que esse resultado pode ser devido a algum resíduo do produto, na carne.

A coloração apresentou valores médios caracterizados entre "vermelho-escura" e "vermelho levemente escura" (2-3 pontos) e a textura variou entre "grosseira" e "levemente grosseira" (2-3 pontos), concordando com Müller (1987), que afirmou que animais mais velhos são propensos a mostrar carne de coloração mais escura e textura mais grosseira.

Realizou-se um teste de correlação de Pearson entre as variáveis, sendo verificado que a maciez foi influenciada pela suculência $\left(r^{2}=0,57 ; P=0,0019\right)$, mostrando que, à medida que aumenta a suculência, a maciez segue a mesma tendência. A quebra no descongelamento da carne, que é a quantidade de líquidos perdidos durante esse processo e a cocção da carne, que é representada pela evaporação e perda de água durante o processo de cozimento, também influenciaram na suculência da carne $\left(\mathrm{r}^{2}=-0,28 ; \mathrm{P}=0,1592 \mathrm{e}\right.$ $r^{2}=-0,40 ; P=0,0395$, respectivamente). Com isso, verificase que, quanto maior o porcentual de perda de líquidos, menor o grau da suculência, concordando com Pacheco et al. (2005). 


\section{CONCLUSÕES}

O farelo de arroz integral e o farelo de trigo apresentaram resultados semelhantes quando utilizados como ingredientes de suplementos na terminação de vacas de descarte.

A inclusão de monensina sódica na dieta de vacas terminadas em campo nativo, recebendo suplementação energética, não influencia no desempenho e nas características da carcaça e da carne.

\section{REFERÊNCIAS BIBLIOGRÁFICAS}

ALVES FILHO, D. C. Evolução do peso e desempenho anual de um rebanho de cria, constituído por fêmeas de diferentes grupos genéticos. 1995. 183 f. Dissertação (Mestrado) - Universidade Federal de Santa Maria, Santa Maria, 1995.

ARBOITTE, M. Z.; RESTLE, J.; ALVES FILHO, D. C.; PASCOAL, L. L.; PACHECO, P. S.; SOCAL, D. C. Características da carcaça de novilhos 5/8 Nelore - 3/8 Charolês abatidos em diferentes estádios de desenvolvimento. Revista Brasileira de Zootecnia, Viçosa, v. 33, n. 4, p. 969-977, 2004.

ASSOCIATION OF ANALITIC CHEMIST. Official methods of analysis. 14. ed. Washington, DC, 1984. 1141 p.

BAVERA, G. A.; PEÑAFORT, C. Condición corporal (CC). In: ____ Curso de producción bovina de carne. Disponível em: <http://www.produccion-animal.com.ar Acesso em: 23 fev. 2007.

BOLING, J. A.; BRADLEY, N. W.; CAMPBELL, L. D. Monensin levels for growing and finishing steers. Journal of Animal Science, Champaign, v. 44, n. 5, p. 867-871, 1977.

CRANCIO, L. A.; CARVALHO, P. C. F.; NABINGER, C.; SILVA, J. L. S.; SANTOS, R. J.; SANTOS, D. T.; PELLEGRINI, L. G. Ganho de peso de novilhas em pastagem nativa da Serra do Sudeste do RS submetida ao controle de plantas indesejáveis e intensidades de pastejo. Ciência Rural, Santa Maria, v. 36, n. 4, p. 1265-1271, 2006.

FREITAS, F. K. de; ROCHA, M. G. da; RESLTE, J.; BRONDANI, I. L.; MACARI, S.; GUTERRES, E. P.; NICOLOSO, C. S. Suplementação energética na recria de fêmeas de corte em pastagem cultivada de inverno. Produção animal. Revista Brasileira de Zootecnia, Viçosa, v. 34, n. 4, p. 1256-1266, 2005.
KUSS, F.; RESTLE, J.; PASCOAL, L. L.; SANTOS, A. P.; MENEZES, L. F. G.; OSMARI, M. P. Desempenho de vacas de descarte recebendo dietas com ou sem monensina. Ciência Rural, Santa Maria, v. 38, n. 1, p. 173-177, jan./ fev. 2008.

LANA, R. P.; RUSSELL, J. B. Efeitos da Monensina sobre a fermentação e sensibilidade de bactérias ruminais de bovinos sob dietas ricas em volumoso ou concentrado. Revista Brasileira de Zootecnia, Viçosa, v. 30, n. 1, p. 254-260, 2001.

MENEZES, L. F. G. de; KOSLOSKI, G. V.; RESTLE, J.; DESCHAPS, F. C.; BRONDANI, I. L.; SANTOS, A. P.; FIAMONCICI, J. Perfil de ácidos graxos de cadeia longa e qualidade da carne de novilhos terminados em confinamento com diferentes níveis de monensina sódica na dieta. Ciência Rural, Santa Maria, v. 36, n. 1, p. 186-190, 2006.

MOOJEN, E. L. Dinâmica e potencial produtivo de uma pastagem nativa do Rio Grande do Sul submetida a pressões de pastejo, épocas de diferimento e níveis de adubação. 1991. 172 f. Tese (Doutorado) - Universidade Federal do Rio Grande do Sul, Porto Alegre, 1991.

MORAES, A. Produtividade animal e dinâmica de uma pastagem de pangola (Digitaria decumbens Stent), azevém (Lolium multiflorum Lam.) e trevo branco (Trifolium repens L.) submetida a diferentes pressões de pastejo. 1991. 200 f. Tese (Doutorado em Zootecnia) - Universidade Federal do Rio Grande do Sul, Porto Alegre, 1991.

MORAES, C. A. C.; FONTES, C. A. A.; LANA, R. P.; SOARES, J. E.; QUEIROZ, A. C.; CAMPOS, J. M. S. Influência da monensina sobre o ganho de peso, consumo e conversão alimentar em bovinos castrados e não castrados. Revista Brasileira de Zootecnia, Viçosa, v. 22, n. 1, p. 71-80, 1993.

MÜLLER, L. Normas para avaliação de carcaças e concurso de carcaças de novilhos. 2. ed. Santa Maria: UFSM, 1987.

NABINGER, C.; SANGUINÉ, E.; MIELITZ NETTO, C. G. A.; WAQUIL, P. D.; MIGUEL, L. A.; SCHNEIDER, S. Diagnóstico de sistemas de produção de bovinocultura de corte do Estado do Rio Grande do Sul: relatório. Porto Alegre: UFRGS, 2005. 265 p.

PACHECO, P. S.; RESTLE, J.; SILVA, J. H. S. Composição física da carcaça e qualidade da carne de novilhos jovens e superjovens de diferentes grupos genéticos. Revista Brasileira de Zootecnia, Viçosa, v. 34, n. 5, p. 1691-1703, 2005. 
RESTLE, J.; NEUMANN, M.; ALVES FILHO, D. C.; PASCOAL, L. L.; ROSA, J. R. P.; MENEZES, L. F. G.; PELLEGRINI, L. G. Terminação em confinamento de vacas e novilhas sob dietas com ou sem monensina sódica. Revista Brasileira de Zootecnia, Viçosa, v. 30, n. 6, p. 18011812, 2001.

RESTLE, J.; PASCOAL, L. L.; ROSA, J. R. P.; FREITAS, A. K.; ALVES FILHO, D. C.; BRONDANI, I. L.; PACHECO, P. S.; MENEZES, L. F. G. Fontes energéticas para bezerros de corte desmamados aos 80 dias de idade. Revista Brasileira de Zootecnia, Viçosa, v. 35, n. 3, p. 1136-1145, 2006. Suplemento.

ROSO, C.; RESTLE, J. Lasalocida sódica suplementada via sal para fêmeas de corte mantidas em pastagem cultivada de estação fria. Revista Brasileira de Zootecnia, Viçosa, v. 30, n. 3, p. 830-834, 2001.

SOARES, A. B.; CARVALHO, P. C. F.; NABINGER, C.; SEMMELMANN, C.; TRINDADE, J. K.; GUERRA, E.; THÉRCIO, S. F.; PINTO, C. E.; FONTOURA JÚNIOR, J. A.;
FRIZZO, A. Produção animal e de forragem em pastagem nativa submetida a distintas ofertas de forragem. Ciência Rural, Santa Maria, v. 35, n. 5, p. 1148-1154, 2005.

SOEST, P. J. van; ROBERTSON, J. B.; LEWIS, B. A. Methods for dietary fiber, neutral detergent fiber, and nonstarch polysaccharides in relation to animal nutrition. Journal of Dairy Science, v. 74, p. 3583-3597, 1991.

VAZ, R. Z. Desenvolvimento reprodutivo de novilhas de corte suplementadas a diferentes níveis de suplementação durante o primeiro período reprodutivo aos 14 meses de idade. 1998. 98 f. Dissertação (Mestrado) - Universidade Federal de Santa Maria, Santa Maria, 1998.

WILM, H. G.; COSTELLO, D. F.; KLIPPLE, G. E. Estimating forage yield by the double-sampling methods. Journal of American Society of Agronomy, Madison, v. 36, p. 194203, 1944.

ZILLER, R. S. R.; ROSA, F. I. Programa global de espécies invasoras. Cidade do Cabo: [s.n.], 2005. 114 p. 